\title{
Value-based evaluation of dialysis versus conservative care in older patients with advanced chronic kidney disease: a cohort study
}

Wouter R. Verberne ${ }^{1 *}$ D, Janneke Dijkers ${ }^{1}$, Johannes C. Kelder ${ }^{2}$, Anthonius B. M. Geers ${ }^{1}$, Wilbert T. Jellema ${ }^{1}$, Hieronymus H. Vincent ${ }^{1}$, Johannes J. M. van Delden ${ }^{3}$ and Willem Jan W. Bos ${ }^{1,4}$

\begin{abstract}
Background: Conservative care is argued to be a reasonable treatment alternative for dialysis in older patients with advanced chronic kidney disease (CKD). However, comparisons are scarce and generally focus on survival only. Comparative data on more patient-relevant outcomes are needed to truly foster shared decision-making on an individual level, and cost comparison is needed to assess value of care.

Methods: We conducted a retrospective observational single-center cohort study in 366 patients aged $\geq 70$ years with advanced CKD, who chose dialysis $(n=240)$ or conservative care $(n=126)$ after careful counselling by a multidisciplinary team in a non-academic teaching hospital in The Netherlands. Using a value-based health care approach (value = outcomes/cost): survival, health-related quality of life-cross-sectionally assessed with the Kidney Disease Quality of Life Short Form ${ }^{\mathrm{TM}}$ — treatment burden, and treatment costs were evaluated.

Results: The overall survival benefit of patients on a dialysis pathway compared with patients on conservative care diminished or lost significance in patients aged $\geq 80$ years or with severe comorbidity. There were no differences between patients managed conservatively and dialysis patients on physical and mental health summary scores (all $P>0.1$ ). Patients on conservative care had 352.7 hospital free days per year versus 282.7 in patients on a dialysis pathway, calculated from treatment decision (adjusted incidence rate ratio: 1.15, 95\% confidence interval: 1.09 to $1.21, P<0.001$ ). Annual treatment costs were lower in patients on conservative care (adjusted cost ratio: $0.43,95 \%$ confidence interval: 0.28 to $0.67, P<0.001$ ).

Conclusions: In this study, conservative care is shown to be a viable treatment option in older patients with advanced CKD, particularly in the oldest old and those with severe comorbidity. By achieving similar outcomes at lower treatment burden and treatment costs, value was generated for older patients choosing conservative care and society.
\end{abstract}

Keywords: Aged, Chronic kidney failure, End-stage renal disease (ESRD), Renal dialysis, Conservative treatment

\footnotetext{
* Correspondence: w.verberne@antoniusziekenhuis.nl

'Department of Internal Medicine, St Antonius Hospital, Koekoekslaan 1, 3435

CMUtrecht, Nieuwegein, The Netherlands

Full list of author information is available at the end of the article
}

(c) The Author(s). 2018 Open Access This article is distributed under the terms of the Creative Commons Attribution 4.0 International License (http://creativecommons.org/licenses/by/4.0/), which permits unrestricted use, distribution, and reproduction in any medium, provided you give appropriate credit to the original author(s) and the source, provide a link to the Creative Commons license, and indicate if changes were made. The Creative Commons Public Domain Dedication waiver (http://creativecommons.org/publicdomain/zero/1.0/) applies to the data made available in this article, unless otherwise stated. 


\section{Background}

In recent years, the number of older patients with advanced chronic kidney disease (CKD) has increased $[1,2]$. As age is no longer seen as contraindication, dialysis treatment in older patients has become an established practice. The majority of dialysis patients is older than 65 years in countries like the United States, the United Kingdom, and The Netherlands nowadays [2-4]. Many older patients with advanced CKD have multiple comorbidities, are frail, and have increased dependency [5]. Dialysis has not always shown to benefit these patients in terms of survival, although evidence is still limited [6-9]. This has raised concerns about the suitability of dialysis - an intensive and expensive treatment-in this setting.

Conservative care (CC) is argued to be a reasonable alternative. In general, CC entails ongoing multidisciplinary care including all types of interventions as needed, though without dialysis [10]. Main goal is preservation of quality of life with adequate symptom control, instead of life prolongation per se. Estimates indicate that up to $15 \%$ of CKD patients choose to forego dialysis and prefer to be managed conservatively [11-13].

Shared decision-making has been recommended to align treatment plan with the patient's values and preferences [14]. However, current decision-making is hampered by limited data on outcomes [10, 15, 16]. Most previous studies focused on survival only. To truly foster decision-making, data on more patient-relevant outcomes are needed [10, 17-19]. We evaluated survival, health-related quality of life (HRQOL), and treatment burden in older patients choosing dialysis or CC. This study is an extension of a previous survival analysis [9]. Treatment costs were assessed to evaluate value of care. This evaluation is based on the concept of value-based health care, in which value of delivered care is defined as the benefits on health outcomes achieved per monetary spent $\quad($ value $=$ outcomes $/$ cost) $[20,21]$. Using this value-based perspective, and by involving patients, our aim was to determine whether $\mathrm{CC}$ is a reasonable treatment option compared to dialysis for older kidney patients and society.

\section{Methods}

\section{Study population}

We identified a retrospective cohort of older patients with stage 4/5 CKD who received nephrology care in our non-academic teaching hospital between October 31, 2004 to May 1, 2016. Patients were included if they had chosen to be treated with dialysis or CC, and if aged $\geq 70$ years at treatment decision. Patients needing immediate start of dialysis at presentation were excluded. As part of standard care, a shared decision-making process on treatment plan was initiated when renal function-determined as estimated glomerular filtration rate (eGFR)- dropped $<20 \mathrm{~mL} / \mathrm{min} / 1.73 \mathrm{~m}^{2}$. A multidisciplinary team consisting of nephrologists, renal nurses, social workers and dieticians carefully counselled patients about possible treatment pathways including CC. In patients choosing haemodialysis (HD) or peritoneal dialysis (PD), dialysis treatment was prepared and initiated once needed. The dialysis group was defined as all who chose dialysis. Hence, the "dialysis group" also includes patients who chose dialysis but have not yet started dialysis at the end of study, and patients who died before initiation. In patients choosing $\mathrm{CC}$, medical treatment and multidisciplinary care were continued. The study was approved by the local research ethics committee.

\section{Demographic and clinical data}

Baseline data collected from electronic medical records included date of birth, sex, primary renal diagnosis according to the European Renal Association-Dialysis and Transplantation Association's codes, comorbidities, height and weight to calculate body mass index, serum albumin level, and C-reactive protein level. Comorbidities were scored according to the Davies comorbidity score, based on the presence of seven comorbid conditions producing three risk groups (see Additional file 1) [22]. Renal function-measured as eGFR with the four-point Modification of Diet in Renal Disease formula [23] - was collected at treatment decision, and when eGFR consistently dropped $<20,<15$, and $<10 \mathrm{~mL} / \mathrm{min} /$ $1.73 \mathrm{~m}^{2}$. Date of death was recorded after verification in the population register.

\section{HRQOL assessment}

All included patients alive in 2015 and 2016 were asked to participate in a cross-sectional assessment of HRQOL. Exclusion criteria were mental incapacitation or language problems of such severity that the informed consent procedure and/or questionnaire could not be completed. The validated Dutch version of the Kidney Disease Quality of Life Short Form (KDQOL-SF ${ }^{\mathrm{TM}}$ ) was used [24, 25]. KDQOL-SF ${ }^{\text {тM }}$ captures both generic and kidney disease-specific domains (see Additional file 1). Questionnaires were self-completed or interviewer-administered. Physical Component Summary (PCS) and Mental Component Summary (MCS) scores were calculated.

\section{Treatment burden}

The outcomes on treatment burden included number of outpatient visits, admissions, in-hospital days, in-center haemodialysis days, and hospital free days as summary measure, comprising all medical specialties in our hospital. Data were collected from electronic medical records. Outcomes were assessed from treatment decision or start of dialysis, until death or end of study. Patients who were lost to follow-up were excluded. Outcomes 
were converted into annual incidence rates to adjust for differences in follow-up length, using total number of events as numerator and total follow-up time in years as denominator [26]. The annual number of hospital free days was estimated using the formula: $365.25-$ (annual number of outpatient visits + in-hospital days + in-center haemodialysis days). In-center haemodialysis days were not counted on in-hospital days to prevent duplications. Further details are available in Additional file 1.

\section{Treatment costs}

Treatment costs were defined as costs incurred through outpatient and inpatient care delivered by all medical specialties. Data were derived from the hospital's financial administration. Due to changes in their system, cost data were reliably available from January 1 , 2008. Treatment costs were assessed from treatment decision or start of dialysis, until death or end of study. Cost rates were annualised to adjust for follow-up length.

\section{Statistical analysis}

Analyses were performed according to original treatment choice and dialysis modality. Patient characteristics were compared using descriptive statistics.

Survival was calculated using the Kaplan-Meier method, with assessment of differences using the log-rank test. Four starting points were used: treatment decision, eGFR $<20,<15$, and $<10 \mathrm{~mL} / \mathrm{min} / 1.73 \mathrm{~m}^{2}$. Adjusted multivariable Cox regression analysis was performed to determine independent predictors of survival, considering: age, sex, primary renal diagnosis, Davies comorbidity score, eGFR at treatment decision, and treatment pathway. The statistically significant and near-significant variables in univariable analysis were used to construct Cox multiple regression models. Backward elimination was used to include only significant predictors of survival in the final model; hence, primary renal diagnosis and eGFR at treatment decision were excluded. Residuals and influential points were checked.

We compared HRQOL between CC patients, patients not yet started on dialysis, and patients started on dialysis. To test differences, students t-tests were used in PCS and MCS, and Mann-Whitney $U$ tests in domain scores. Adjusted multiple linear regression analyses were performed on PCS and MCS to evaluate the association with treatment pathway, adjusting for: age, sex, Davies comorbidity score, and way of administration (self or by interviewer).

Incidence rate ratios were estimated to test differences in treatment burden outcomes, using generalised linear regression models with negative binomial distributionas data were not normally distributed and overdispersed.
Incidence rate ratios are interpreted similarly as odds ratios [26]. Adjustment variables were age, sex, Davies comorbidity score, and eGFR.

We report the mean annual treatment costs-recommended as most informative measure for cost data [27] - although cost data were not normally distributed. Negative binomial regression was used to assess differences by estimating the cost ratio. Adjustment variables were age, sex, Davies comorbidity score, and eGFR. Sensitivity analysis was performed-as recommended [28] - to test best model fit using generalised linear regression models with log-gamma and Poisson distribution.

A $P$ value $<0.05$ was considered statistically significant. Statistical analyses were performed using IBM SPSS 24.0.

\section{Patient involvement}

In collaboration with the Dutch Kidney Patients Association, two patient representatives and a policy adviser of the Association were involved in designing the study. A systematic evaluation of our research protocol was performed using a guideline developed by the Association. Together with the Association, we also organized a group discussion with six patient representatives to interpret the results from patients' perspectives.

\section{Results}

Overall, we included 366 patients: 240 choosing dialysis, and 126 choosing CC (Fig. 1). Few patients changed their treatment choice: fifteen changed their original choice in favour of dialysis into $\mathrm{CC}$, and four from $\mathrm{CC}$ into dialysis. Six patients underwent kidney transplantation, five after dialysis initiation (censored at date of transplantation). Baseline characteristics are shown in Table 1. Compared to the dialysis group, CC patients were older, more often female, and their eGFR at treatment decision was higher. There were no differences in Davies comorbidity score, primary renal diagnosis, body mass index, serum albumin, and C-reactive protein level.

\section{Survival}

The dialysis group lived approximately twice as long compared to the CC group (Fig. 2a; median survival from eGFR $<20 \mathrm{~mL} / \mathrm{min} / 1.73 \mathrm{~m}^{2}: 4.3$ [2.1-7.6] versus 2.4 [1.4-3.7] years, $P<0.001)$. However, this significant survival advantage of the dialysis group disappeared in patients aged $\geq 80$ years (Fig. 2 b, c; median survival: 2.9 [1.9-6.0] versus 2.3 [1.3-3.7] years, $P=0.13)$. The survival advantage of the dialysis group also lost significance in patients aged $\geq 70$ years with Davies comorbidity scores $\geq 3$ (severe comorbidity) (Fig. 2d, e; median 


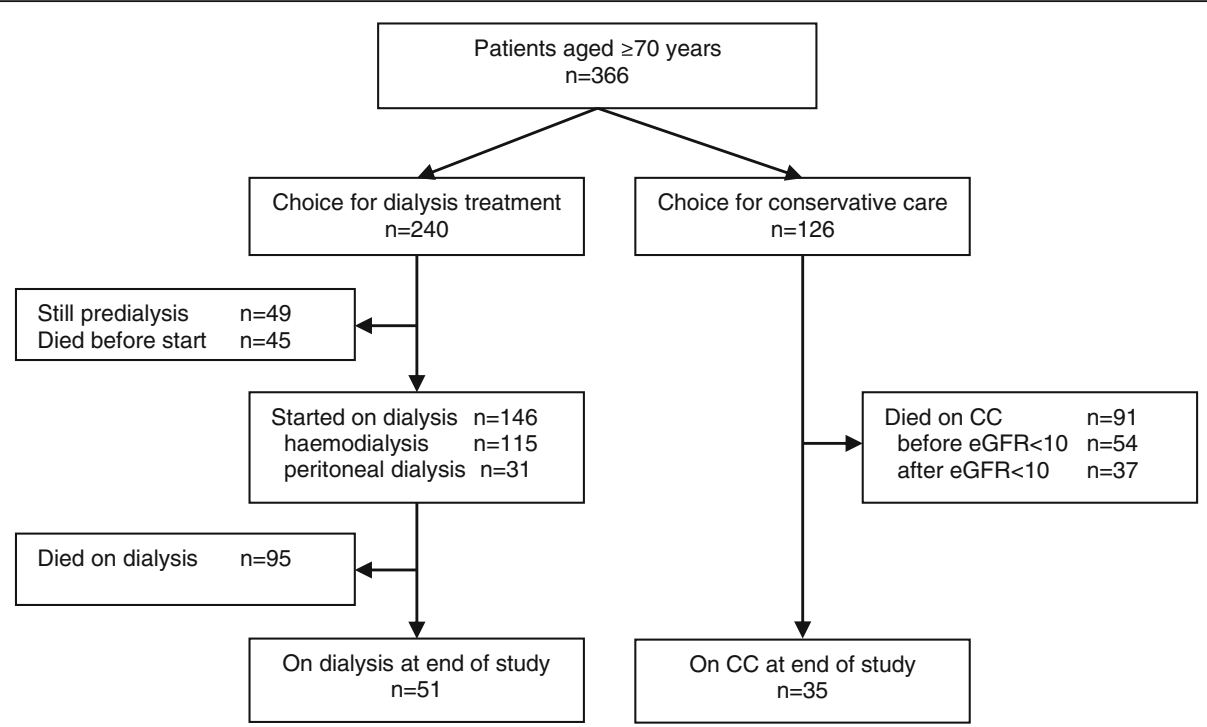

Fig. 1 Overall flow of patients $\geq 70$ years with advanced chronic kidney disease (stage 4/5). Fifteen patients changed their original choice in favour of dialysis to conservative care, and four changed from conservative care to dialysis. Analyses were based on the original treatment choice. CC, conservative care; eGFR, estimated glomerular filtration rate $\left(\mathrm{mL} / \mathrm{min} / 1.73 \mathrm{~m}^{2}\right)$

Table 1 Baseline characteristics of patients choosing dialysis or conservative care, determined at treatment decision

\begin{tabular}{|c|c|c|c|}
\hline & Dialysis $(n=240)$ & Conservative care $(n=126)$ & $P$ value \\
\hline Age (years), mean (SD) & $76.2(4.4)$ & $82.6(4.5)$ & $<0.001$ \\
\hline Aged $\geq 80$ years & $55(23 \%)$ & $93(74 \%)$ & $<0.001$ \\
\hline Sex (female) & $80(33 \%)$ & $58(46 \%)$ & 0.02 \\
\hline Davies comorbidity score & & & 0.73 \\
\hline No comorbidity (score = 0) & $27(11 \%)$ & $11(9 \%)$ & \\
\hline Intermediate comorbidity (score $=1$ or 2 ) & $142(59 \%)$ & $75(59 \%)$ & \\
\hline Severe comorbidity (score $\geq 3$ ) & $71(30 \%)$ & $40(32 \%)$ & \\
\hline Primary renal diagnoses & & & 0.12 \\
\hline Renal vascular disease & $82(34 \%)$ & $58(46 \%)$ & \\
\hline Diabetes mellitus & $40(17 \%)$ & $16(13 \%)$ & \\
\hline Hypertension & $21(9 \%)$ & $7(6 \%)$ & \\
\hline Pyelonephritis & $5(2 \%)$ & $5(4 \%)$ & \\
\hline Polycystic kidneys & $7(3 \%)$ & $1(1 \%)$ & \\
\hline Glomerulonephritis & $7(3 \%)$ & $0(0 \%)$ & \\
\hline Cause unknown & $58(24 \%)$ & $30(24 \%)$ & \\
\hline Other & $20(8 \%)$ & $9(7 \%)$ & \\
\hline Body mass index $\left(\mathrm{kg} / \mathrm{m}^{2}\right)$, mean (SD) & $27.0(4.5 ; n=196)$ & $26.2(4.8 ; n=98)$ & 0.16 \\
\hline Albumin $(g / l)$, mean (SD) & $39.2(4.6 ; n=186)$ & $38.8(3.5 ; n=109)$ & 0.42 \\
\hline C-reactive protein $(\mathrm{nmol} / \mathrm{I})$, median (IQR) & $47.6(28.6-95.2 ; n=173)$ & $47.6(28.6-123.8 ; n=93)$ & 0.12 \\
\hline eGFR at treatment decision $\left(\mathrm{mL} / \mathrm{min} / 1.73 \mathrm{~m}^{2}\right)$, mean $(\mathrm{SD})$ & $13.3(4.3)$ & $15.6(5.0)$ & $<0.001$ \\
\hline $\begin{array}{l}\text { Time of eGFR decline from }<20 \text { to }<15 \mathrm{~mL} / \mathrm{min} / 1.73 \mathrm{~m}^{2} \\
\text { (days), median (IQR) }\end{array}$ & $238(52-461 ; n=188)$ & $212(0-564 ; n=80)$ & 0.55 \\
\hline $\begin{array}{l}\text { Time from treatment decision to dialysis initiation (days), } \\
\text { median (IQR) }\end{array}$ & $146(48-437 ; n=146)$ & & \\
\hline eGFR at start of dialysis $\left(\mathrm{mL} / \mathrm{min} / 1.73 \mathrm{~m}^{2}\right)$, mean (SD) & $8.4(2.9 ; n=146)$ & & \\
\hline
\end{tabular}




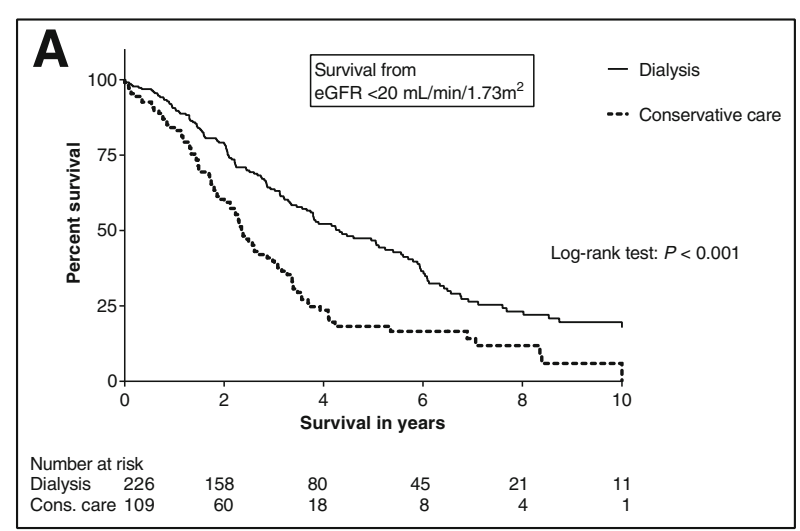

Age 70-80 years

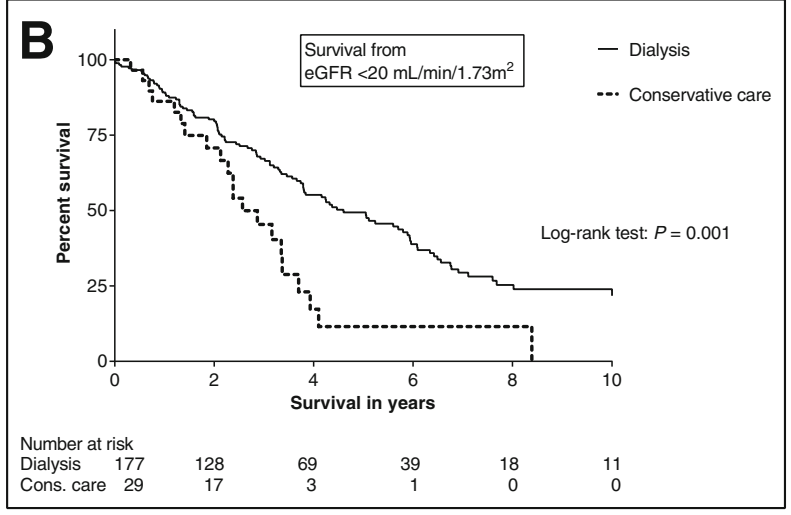

No or intermediate comorbidity

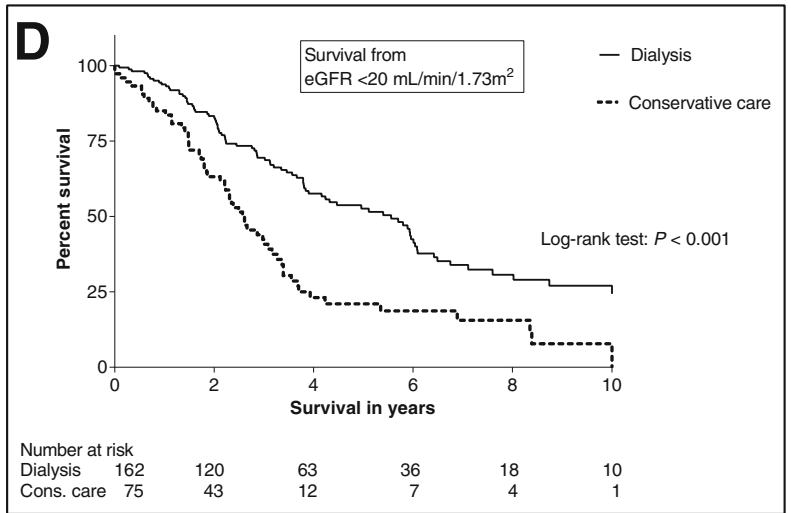

Age $\geq 80$ years

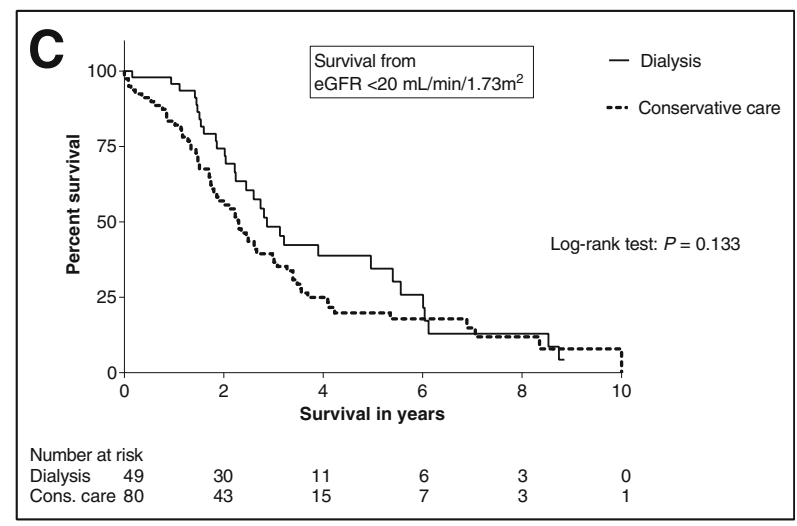

Severe comorbidity

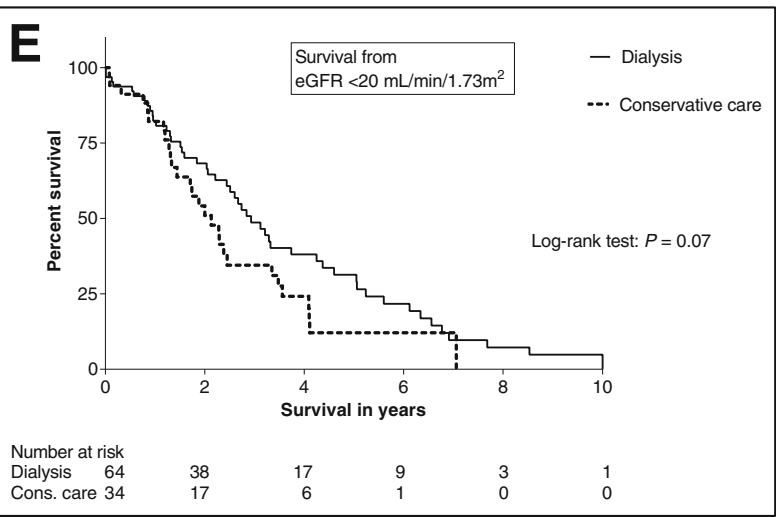

Fig. 2 Kaplan-Meier survival curves comparing patients $\geq 70$ years choosing dialysis or conservative care, from eGFR $<20 \mathrm{~mL} / \mathrm{min} / 1.73 \mathrm{~m}{ }^{2}$ : overall comparison of both groups (part a; median survival: 4.3 [2.1-7.6] versus 2.4 [1.4-3.7] years); after stratification of age (b and c); after stratification of Davies comorbidity scores with no and intermediate comorbidity taken together versus severe comorbidity (d and $\mathbf{e}$ ). The total number of included patients in this analysis was lower because some were referred after eGFR $<20 \mathrm{~mL} / \mathrm{min} / 1.73 \mathrm{~m}^{2}$. See Additional files 2,3 and 4 for the survival curves from the other starting points (treatment decision, eGFR $<15$ and $<10 \mathrm{~mL} / \mathrm{min} / 1.73 \mathrm{~m}^{2}$ )

survival: $2.9[1.5-5.2]$ versus $2.1[1.3-3.6]$ years, $P=$ 0.07). Similar results were found using the other starting points (treatment decision, eGFR $<15$ and $<10 \mathrm{~mL} / \mathrm{min} /$ $\left.1.73 \mathrm{~m}^{2}\right)$ : the significant survival benefit of the dialysis group diminished or disappeared in patients aged $\geq 80$ years or with severe comorbidity (see Additional files 2, 3 and 4). Adjusted multivariable Cox regression analysis confirmed the observations that increasing age and severe comorbidity were independently associated with higher mortality (Table 2). 
Table 2 Multivariable Cox proportional hazards model of survival in 240 patients choosing dialysis and 126 patients choosing conservative care, calculated from treatment decision

\begin{tabular}{llll}
\hline & Hazard ratio & $\begin{array}{l}95 \% \text { Cl for } \\
\text { Hazard Ratio }\end{array}$ & $P$ value \\
\hline Age (years) & 1.04 & 1.01 to 1.07 & 0.02 \\
$\begin{array}{l}\text { Female vs. Male } \\
\begin{array}{l}\text { Davies comorbidity } \\
\text { score }\end{array}\end{array}$ & 0.74 & 0.56 to 0.98 & 0.04 \\
$\quad \begin{array}{lll}\text { Intermediate comorbidity } \\
\text { vs. No comorbidity }\end{array}$ & 1.79 & 1.04 to 3.07 & $<0.001$ \\
$\quad \begin{array}{l}\text { Severe comorbidity vs. } \\
\quad \text { No comorbidity }\end{array}$ & 3.48 & 1.99 to 6.11 & \\
\begin{tabular}{l} 
Conservative care vs. Dialysis \\
\hline
\end{tabular} & 1.67 & 1.19 to 2.35 & 0.003 \\
\hline
\end{tabular}

$\mathrm{Cl}$ confidence interval, vs versus

\section{HRQOL}

99 (77\%) of 128 eligible patients consented for HRQOL assessment. Main reasons for non-participation were assumed response burden $(n=9)$, or unknown (17 non-responders). Three patients were excluded from analysis because of too many missings, leaving 96 patients (baseline characteristics: see Additional file 5). Of 34 dialysis patients, 26 were on $\mathrm{HD}$, and 8 on PD.

Table 3 shows the results on PCS and MCS, and three kidney disease-specific domains of KDQOL-SF ${ }^{\mathrm{TM}}$ (all domain scores: see Additional file 6). No significant differences were found between dialysis patients and CC patients on PCS, MCS, symptoms, and effects of kidney disease. Dialysis patients scored worst on burden of kidney disease. Compared to patients not yet started on dialysis, CC patients scored significantly lower on PCS, MCS, symptoms, and effects of kidney disease on daily life, while no differences were observed on burden of kidney disease. After adjustment, multiple linear regression models confirmed the observations on PCS and MCS (Table 4).

\section{Treatment burden}

358 patients were included in the analyses on treatment burden: 233 in the dialysis group (602.1 person years), and 125 in the CC group (198.7 person years), excluding 8 who were lost to follow-up due to referall to other centers. Of 233 patients in the dialysis group, 140 started dialysis.

Table 5 shows the results for treatment burden. CC patients had significant lower treatment burden compared with the dialysis group: less outpatient visits, admissions, and in-hospital days, resulting in more hospital free days (part A). The adjusted incidence rate ratios confirmed these findings. In the dialysis group, the overall incidence rate of in-center haemodialysis days calculated from treatment decision was 60.6 days per person year (hence, also capturing time between treatment decision and dialysis initiation). The number of in-center haemodialysis days calculated from start of dialysis in haemodialysis patients only $(n=110)$ was 150.3 days per person year, resulting in less hospital free days (part B).

\section{Treatment costs}

Cost data were available for 262 patients: 162 choosing dialysis (380.7 person years), 100 choosing CC (153.2 person years). Of 162 patients choosing dialysis, 84 started dialysis. Baseline characteristics were similar compared with the overall cohort.

Table 6 shows the results on treatment costs incurred in our hospital, indicating significant lower costs in the

Table 3 Physical and mental component summary scores ${ }^{\mathrm{a}}$, and three kidney disease-specific domain Scores $^{\mathrm{a}}$ from $\mathrm{KDQOL}^{-S F^{\mathrm{T}}}$

\begin{tabular}{|c|c|c|c|c|}
\hline & $\begin{array}{l}\text { Not yet started on dialysis } \\
(n=39)\end{array}$ & $\begin{array}{l}\text { Started on dialysis } \\
(n=34)\end{array}$ & $\begin{array}{l}\text { Conservative care } \\
(n=23)\end{array}$ & $P$ value \\
\hline $\begin{array}{l}\text { Physical Component Summary score, } \\
\text { mean (SD) }\end{array}$ & $56.0(20.6)$ & $48.1(20.9)$ & $40.2(16.2)$ & $\begin{array}{l}1:<0.01^{b} \\
2: 0.14^{c} \\
3: 0.11^{d}\end{array}$ \\
\hline Mental Component Summary score, mean (SD) & $68.5(17.2)$ & $62.0(22.0)$ & $54.2(19.7)$ & $\begin{array}{l}1:<0.01 \\
2: 0.18 \\
3: 0.16\end{array}$ \\
\hline $\begin{array}{l}\text { Kidney disease-specific symptoms and } \\
\text { problems, median (IQR) }\end{array}$ & $86.4(68.2-88.6)$ & $83.3(70.6-89.6)$ & $72.6(61.4-83.0)$ & $\begin{array}{l}1: 0.03 \\
2: 0.05 \\
\text { 3: } 0.81\end{array}$ \\
\hline $\begin{array}{l}\text { Effects of kidney disease on daily life, } \\
\text { median (IQR) }\end{array}$ & $92.9(78.6-96.4)$ & $85.7(67.9-96.4)$ & $82.7(58.9-90.2)$ & $\begin{array}{l}1: 0.03 \\
2: 0.35 \\
3: 0.26\end{array}$ \\
\hline Burden of kidney disease, median (IQR) & $75.0(56.3-93.8)$ & $43.8(25.0-62.5)$ & $75.0(56.3-81.3)$ & $\begin{array}{l}1: 0.70 \\
2: 0.001 \\
3:<0.001\end{array}$ \\
\hline
\end{tabular}

$I Q R$ interquartile range, $K D Q O L-S F^{\mathrm{TM}}$, Kidney Disease Quality of Life Short Form, SD standard deviation

$\mathrm{a}=$ Scores range between 0 and 100; higher scores indicate better health-related quality of life

$\mathrm{b}=$ Not yet started on dialysis versus Conservative care;

${ }^{c}=$ Started on dialysis versus Conservative care;

$\mathrm{d}=$ Not yet started on dialysis versus Started on dialysis 
Table 4 Multiple linear regression models of the PCS and MCS from KDQOL-SF ${ }^{\mathrm{TM}}$ in patients choosing dialysis but not yet started on dialysis $(n=39)$, in patients started on dialysis $(n=34)$, and in patients choosing conservative care $(n=23)$

\begin{tabular}{|c|c|c|c|}
\hline & B & $95 \% \mathrm{Cl}$ for $\mathrm{B}$ & $P$ value \\
\hline \multicolumn{4}{|l|}{ Physical Component Summary score ${ }^{a}$} \\
\hline Constant & 41.31 & 32.54 to 50.09 & \\
\hline Female vs. Male & -10.01 & -18.28 to -1.73 & 0.02 \\
\hline Interviewer-administration vs. Self-administration & 14.23 & 5.63 to 22.84 & 0.001 \\
\hline Not yet started on dialysis vs. Conservative care & 15.24 & 5.46 to 25.03 & 0.003 \\
\hline Started on dialysis vs. Conservative care & 1.58 & -8.87 to 12.04 & 0.76 \\
\hline \multicolumn{4}{|l|}{ Mental Component Summary score ${ }^{b}$} \\
\hline Constant & 48.82 & 41.30 to 56.34 & \\
\hline Interviewer-administration vs. Self-administration & 20.49 & 12.41 to 28.57 & $<0.001$ \\
\hline Not yet started on dialysis vs. Conservative care & 16.03 & 6.90 to 25.16 & 0.001 \\
\hline Started on dialysis vs. Conservative care & 2.01 & -7.67 to 11.69 & 0.68 \\
\hline
\end{tabular}

CC group. The cost ratio-after adjustment for age, sex, Davies comorbidity score, and eGFR-was 0.43 (95\% CI 0.28 to $0.67, P<0.001)$. Results were similar in sensitivity analyses fitting generalised linear models with log-y or Poisson distribution.

\section{Discussion}

In this retrospective observational cohort study, we evaluated a combination of patient-relevant outcomes and treatment costs in one of the largest groups reported so far of older patients ( $\geq 70$ years) with advanced CKD who have chosen to be treated with dialysis or CC. Patients choosing dialysis lived longer compared with patients choosing $\mathrm{CC}$, but there was little or no significant survival advantage in patients aged $\geq 80$ years or with severe comorbidity. In a smaller subset, no significant differences were observed in physical and mental health scores between patients on dialysis or CC, while dialysis patients scored worst on burden of kidney disease. Treatment burden was substantially lower in

Table 5 Outcomes on treatment burden. Annual treatment burden of patients choosing dialysis versus patients choosing conservative care, measured from treatment decision (part A). Annual treatment burden of patients started on dialysis—a subgroup of all patients choosing dialysis-measured from start of dialysis (part B)

\begin{tabular}{|c|c|c|c|c|}
\hline A - from treatment decision & $\begin{array}{l}\text { Dialysis ( } n=233 \text { ) } \\
\text { Incidence rate }\end{array}$ & $\begin{array}{l}\text { Conservative care }(n=125) \\
\text { Incidence rate }\end{array}$ & $\begin{array}{l}\text { Incidence rate ratio }{ }^{b} \\
(95 \% \mathrm{Cl})\end{array}$ & $P$ value \\
\hline Outpatient visits per person year & 11.1 & 6.6 & 0.63 (0.53 to 0.75$)$ & $<0.001$ \\
\hline Admissions per person year & 2.0 & 1.1 & $0.57(0.42$ to 0.78$)$ & $<0.001$ \\
\hline In-hospital days per person year & 10.8 & 6.0 & $0.43(0.28$ to 0.66$)$ & $<0.001$ \\
\hline $\begin{array}{l}\text { In-center haemodialysis days per } \\
\text { person year }\end{array}$ & 60.6 & - & - & - \\
\hline Hospital free days per person year ${ }^{a}$ & 282.7 & 352.7 & $1.15(1.09$ to 1.21$)$ & $<0.001$ \\
\hline B - from start of dialysis & $\begin{array}{l}\text { Haemodialysis }(n=110) \\
\text { Incidence rate }\end{array}$ & $\begin{array}{l}\text { Peritoneal dialysis }(n=30) \\
\text { Incidence rate }\end{array}$ & $\begin{array}{l}\text { Incidence rate ratio }{ }^{c} \\
(95 \% \mathrm{Cl})\end{array}$ & $P$ value \\
\hline Outpatient visits per person year & 9.0 & 15.2 & $1.80(1.43$ to 2.26$)$ & $<0.001$ \\
\hline Admissions per person year & 2.4 & 2.3 & $1.03(0.71$ to 1.49$)$ & 0.88 \\
\hline In-hospital days per person year & 14.6 & 14.8 & 1.46 (0.80 to 2.68$)$ & 0.22 \\
\hline $\begin{array}{l}\text { In-center haemodialysis days per } \\
\text { person year }\end{array}$ & 150.3 & - & - & - \\
\hline Hospital free days per person year ${ }^{a}$ & 191.4 & 335.4 & $1.72(1.65$ to 1.80$)$ & $<0.001$ \\
\hline
\end{tabular}

$\mathrm{a}=$ Hospital free days are calculated using the formula: 365.25 - (annual incidence rates of outpatient visits + in-hospital days + in-center haemodialysis days)

${ }^{b}=$ Adjusted for age, sex, Davies comorbidity score, and estimated glomerular filtration rate

${ }^{c}=$ Adjusted for age, sex, and Davies comorbidity score 
Table 6 Treatment costs. Mean annual treatment costs of patients choosing dialysis versus patients choosing conservative care, measured from treatment decision (part A). Mean annual treatment costs of patients started on dialysis-a subgroup of all patients choosing dialysis-measured from start of dialysis (part B)

\begin{tabular}{|c|c|c|c|c|}
\hline A - from treatment decision & Dialysis $(n=162)$ & Conservative care $(n=100)$ & Cost ratio ${ }^{a}(95 \% \mathrm{Cl})$ & $P$ value \\
\hline Costs per person year, $€$ & 28,353 & 5861 & 0.43 (0.28 to 0.67$)$ & $<0.001$ \\
\hline B - from start of dialysis & $\begin{array}{l}\text { Started on dialysis ( } n=84 ; 64 \\
\text { on HD; } 20 \text { on PD) }\end{array}$ & & & \\
\hline Costs per person year, $€$ & 54,907 & & & \\
\hline
\end{tabular}

adjusted for age, sex, Davies comorbidity score, and estimated glomerular filtration rate

patients on $\mathrm{CC}$, including less frequent outpatient visits, admissions, in-hospital days, and no in-center haemodialysis days, resulting in more hospital free days. CC patients incurred significantly lower treatment costs in our hospital. By carefully delivering patient-centered care with shared decision-making on treatment plan, value was generated for patients choosing $\mathrm{CC}$ and society by achieving similar outcomes at lower treatment burden and treatment costs.

To inform shared decision-making on dialysis or conservative care, data on patient-relevant outcomes are needed. Studies comparing older patients on dialysis and CC have been cohort or case-control studies, with the majority being retrospective, small, single-center, and from the United Kingdom [6-8]. Appropriate comparison of results across these studies is hindered by methodological issues including heterogeneous populations, allocation bias, and variation in definition of time points used in analysis. Whilst a randomized controlled trial offers a more ideal study design to compare outcomes between groups, such study design in this setting would pose difficult, if not impossible, ethical and practical dilemmas and has not been reported so far.

Survival has been studied most frequently, and is regarded as important outcome by kidney patients [16-19]. In general, all survival studies showed a significant survival advantage in the dialysis group, but there was little or no significant survival benefit when comparison was restricted to patients with high age or high comorbidity scores $[6-8,29,30]$. Best available evidence comes from a prospective study [31], the relatively largest retrospective study performed so far [32], and two smaller retrospective studies [33, 34]. We found similar results in a large Dutch population aged $\geq 70$ years, comparable with our previous survival analysis (see Additional file 7) [9]. Due to differences between studies in design and findings, it is difficult to identify a consistent cut-off level for age or comorbidity score from which the survival advantage of dialysis is no longer significant. While a cut-off level could be useful to help identify which patients are likely to benefit from dialysis, there is great risk of oversimplifying decision-making, for example by overlooking relevant individual factors. It should also be noted that the results of the subgroup analyses based on age and comorbidity have to be interpreted with caution, as the patient numbers in the subgroups are lower. We think that the most appropriate conclusions on survival so far are that 1) increasing age and comorbidity are associated with decreasing survival benefit in patients choosing dialysis compared to choosing $\mathrm{CC}$, and that 2) the survival advantage of dialysis is no longer significant in patients with the highest ages and severe comorbidity.

HRQOL is one of the most important outcomes to kidney patients [16-19, 35], but studies comparing HRQOL between dialysis and CC are limited [36]. HRQOL has mostly been assessed with the generic Short Form-36 (SF-36) [31, 37-40]. In general, CC patients are found to have similar PCS and MCS scores compared to patients on a dialysis pathway. Our results, although determined in small groups, are consistent with these findings. Two studies observed a lower PCS score at baseline in the CC group compared to patients on a dialysis pathway, but this difference can be explained by the significant group differences in age and comorbidity $[31,37]$. In our study, there were no differences in comorbidity scores, and age differences were substantially smaller. The observed difference in PCS scores in one study [37] can also be explained by including predialysis and dialysis patients in one overall dialysis group. We found significant differences between these groups, and therefore believe that separating these dialysis subgroups is essential to perform meaningful comparisons on HRQOL. Kidney disease-specific domains of HRQOL have been assessed by only one study so far, using KDQOL-SF ${ }^{\text {mix }}$ [40]. Seow et al. observed that dialysis initiation was associated with worse scores on burden of kidney disease, and effects of kidney disease on daily life [40]. We also observed the worst scores on burden of kidney disease in dialysis patients. To confirm the findings on HRQOL and truly inform decision-making, longitudinal HRQOL assessments-capturing generic and kidney disease-specific domains- in larger cohorts are needed.

Treatment burden is shown to be very relevant to kidney patients, particularly when considering dialysis or 
CC [16-19, 35, 41]. Only few studies have compared treatment burden so far, although detailed definitions are often missing-for example whether in-center haemodialysis days or outpatient visits were assessed [32, 42-45]. In general, patients on a dialysis pathway are observed to have higher hospitalization rates and to spend more time in hospital compared with CC patients. Our results are consistent with these findings while providing more insight in different domains of treatment burden. By doing so, we were able to estimate the number of hospital free days as summary measure. Although the burden of each domain could be experienced differently, hospital free time is shown to be one of most relevant outcomes to kidney patients and could be a major reason for older patients to choose CC instead of dialysis [17-19, 41, 46].

We assessed treatment costs to determine value of care. Whilst cost data will not help patients in their decision-making, insight is needed for other stakeholders like health policy makers and society. Unsurprisingly, we observed lower treatment costs in patients on CC. Only three previous studies compared costs in patients on dialysis or CC. All reported lower costs in the CC group [42, 47, 48], despite methodological issues [49]. Comprehensive economic evaluations are needed to confirm these results [49].

Our observational study addresses the knowledge gap on patient-relevant outcomes and value of care in older kidney patients treated with dialysis or CC, and will help inform decision-making on preferred treatment. Potential flaws are allocation bias and confounding by indication, both inherent to the non-random treatment decision. In our cohort, the CC group was substantially older compared with the dialysis group, whilst comorbidity-which often differs between both groups in other studies $[6,8]$-was similar. We confirmed our findings in multivariable regression analyses with adjustment for several confounders. However, residual confounders might be missing. Bias could also be present due to the sample size, particularly in our HRQOL assessment. Our findings primarily stress the need for larger comparative studies focusing on more than survival only.

A methodological difficulty in outcome comparisons between dialysis and conservative care is to define equivalent time points for both treatment pathways. Theoretically, the best possible starting point would be the start of dialysis, representing the moment that each group starts receiving their specific treatment. However, this time point is not applicable in CC patients and identifying an equivalent moment of a putative or assumed dialysis start is difficult [8]. The use of other time points means that observed outcomes are not the exclusive result of received treatment but rather are associated with being in the group who chose dialysis or CC. Like many other studies [31, 37, 50-52], we used time of treatment decision as starting point. A concern about this time point is that lead time bias might be present, indicated in our study by a significant difference in eGFR at treatment decision between both patient groups. Therefore, we also used three time points reaching a threshold eGFR in survival analyses, and adjusted for eGFR at treatment decision in the multivariable regression analyses of survival, treatment burden, and treatment costs.

As data on treatment burden and treatment costs were only available from our hospital, potential data from other hospitals, primary care, social services, nursing homes, and on out-of-hospital medication are missing. Such data are required to fully assess whether value has been increased by taking into account the entire care pathway. We see our evaluation as a first step.

\section{Conclusions}

We studied a combination of patient-relevant outcomes and treatment costs, and showed that patients $\geq 70$ years choosing CC instead of dialysis-particularly the oldest old and those with severe comorbidity-achieved similar survival and HRQOL outcomes at lower treatment burden and treatment costs. We believe CC to be a viable treatment option in older CKD patients. With CC, value of care can be generated: for patients in terms of patient-relevant outcomes in balance with treatment burden; for society in terms of patient-relevant outcomes per monetary unit spent. These findings emphasize the need to openly discuss all treatment options including $\mathrm{CC}$ to align treatment plan with what matters to older patients with advanced CKD.

\section{Additional files}

Additional file 1: Methods. Details on the Davies comorbidity score, KDQOL-SF ${ }^{\mathrm{TM}}$, and treatment burden outcomes. (PDF $16 \mathrm{~kb}$ )

Additional file 2: Figure S1. Kaplan-Meier survival curves comparing patients $\geq 70$ years choosing dialysis or conservative care, from treatment decision. (PDF $87 \mathrm{~kb}$ )

Additional file 3: Figure S2. Kaplan-Meier survival curves comparing patients $\geq 70$ years choosing dialysis or conservative care, from eGFR < $15 \mathrm{~mL} / \mathrm{min} / 1.73 \mathrm{~m}^{2}$. (PDF $91 \mathrm{~kb}$ )

Additional file 4: Figure S3. Kaplan-Meier survival curves comparing patients $\geq 70$ years choosing dialysis or conservative care, from eGFR < $10 \mathrm{~mL} / \mathrm{min} / 1.73 \mathrm{~m}^{2}$. (PDF $76 \mathrm{~kb}$ )

Additional file 5: Table S1. Baseline characteristics of patients included in the assessment of HRQOL. (PDF $12 \mathrm{~kb}$ )

Additional file 6: Table S2. All KDQOL-SF ${ }^{\mathrm{TM}}$ domain scores in patients choosing dialysis but not yet started on dialysis, in patients started on dialysis, and in patients on conservative care. (PDF 7 kb)

Additional file 7: Discussion. Comparison between the current and previous results on survival. (PDF $11 \mathrm{~kb}$ )

\section{Abbreviations}

CC: Conservative care; Cl: Confidence interval; CKD: Chronic kidney disease; eGFR: Estimated glomerular filtration rate; HD: Haemodialysis; HRQOL: Healthrelated quality of life; KDQOL-SF'M. Kidney disease quality of life short form; 
MCS: Mental component summary; PCS: Physical component summary; PD: peritoneal dialysis; SF-36: Short form-36; SPSS: Statistical package for the social science

\section{Acknowledgements}

We thank the patient representatives and the Dutch Kidney Patients Association (Nierpatiënten Vereniging Nederland) for their input in setting the research questions, outcome measures, and study design; for critically reading the manuscript; and for their input in the group discussion on the interpretation of the study results.

\section{Funding}

The study was funded by an unrestricted grant from the St. Antonius Research Fund, from Roche (Woerden, The Netherlands) to the St. Antonius Research Fund, and from Zilveren Kruis Health Insurance. The funders played no role in study design; collection, analysis, and interpretation of data; writing of the report; or in the decision to submit the article for publication.

\section{Availability of data and materials}

The datasets used and/or analysed during the current study are available from the corresponding author on reasonable request.

\section{Authors' contributions}

Research idea and study design: WV, JVD, WB; data acquisition: WV, JD; data analysis and interpretation: WV, JD, JK, AG, WJ, HV, JVD, WB; statistical analysis: W, JD, JK, WB; supervision or mentorship: JVD, WB. All authors read and approved the final manuscript.

\section{Ethics approval and consent to participate}

Ethical approval was obtained from the local research ethics committee (Verenigde Commissies Mensgebonden Onderzoek; reference W14.053). Informed written consent was obtained from patients prior to data collection.

\section{Consent for publication}

not applicable.

\section{Competing interests}

W was research fellow of the International Consortium for Health Outcomes Measurement (ICHOM) Chronic Kidney Disease (CKD) Working Group. WB chaired the ICHOM CKD Working Group. All authors declare no financial conflict of interest.

\section{Publisher's Note}

Springer Nature remains neutral with regard to jurisdictional claims in published maps and institutional affiliations.

\section{Author details}

'Department of Internal Medicine, St Antonius Hospital, Koekoekslaan 1, 3435 CMUtrecht, Nieuwegein, The Netherlands. ${ }^{2}$ Department of Clinical Epidemiology and Medical Statistics, St Antonius Hospital, Nieuwegein, Utrecht, The Netherlands. ${ }^{3}$ University Medical Centre Utrecht, Julius Centre for Health Sciences and Primary Care, Utrecht, The Netherlands. ${ }^{4}$ Department of Internal Medicine, Leiden University Medical Center, Leiden, Zuid-Holland, The Netherlands.

Received: 6 June 2018 Accepted: 6 August 2018

Published online: 16 August 2018

\section{References}

1. Couser WG, Remuzzi G, Mendis S, Tonelli M. The contribution of chronic kidney disease to the global burden of major noncommunicable diseases. Kidney Int. 2011;80(12):1258-70.

2. Saran R, Robinson B, Abbott KC, Agodoa LY, Ayanian J, Bragg-Gresham J, et al. US Renal Data System 2016 Annual Data Report: Epidemiology of Kidney Disease in the United States. Am J Kidney Dis. 2017;69(3S1):A7-8.

3. Gilg J, Caskey F, Fogarty D. UK renal registry 18th annual report: chapter 1 UK renal replacement therapy incidence in 2014: national and Centrespecific analyses. Nephron. 2016;132(Suppl 1):9-40.

4. Hoekstra T, Hemmelder M, Van Ittersum F. RENINE annual report 2015 Available from: http://www.nefrovisie.nl/wp-content/uploads/2017/03/ RENINE-year-report_08032017.pdf. Accessed 1 May 2017.
5. Kallenberg MH, Kleinveld HA, Dekker FW, van Munster BC, Rabelink TJ, van Buren $\mathrm{M}$, et al. Functional and cognitive impairment, frailty, and adverse health outcomes in older patients reaching ESRD-A systematic review. Clin J Am Soc Nephrol. 2016;11(9):1624-39.

6. O'Connor NR, Kumar P. Conservative management of end-stage renal disease without dialysis: a systematic review. J Palliat Med. 2012;15(2):228-35.

7. Murtagh FE, Burns A, Moranne O, Morton RL, Naicker S. Supportive care: comprehensive conservative Care in end-Stage Kidney Disease. Clin J Am Soc Nephrol. 2016;11(10):1909-14.

8. Hole B, Tonkin-Crine S, Caskey FJ, Roderick P. Treatment of end-stage kidney failure without renal replacement therapy. Semin Dial. 2016;29(6):491-506.

9. Verberne WR, Geers AB, Jellema WT, Vincent HH, van Delden JJ, Bos WJ. Comparative survival among older adults with advanced kidney disease managed conservatively versus with Dialysis. Clin J Am Soc Nephrol. 2016; 11(4):633-40.

10. Davison SN, Levin A, Moss AH, Jha V, Brown EA, Brennan F, et al. Executive summary of the KDIGO controversies conference on supportive Care in Chronic Kidney Disease: developing a roadmap to improving quality care. Kidney Int. 2015:88(3):447-59.

11. van de Luijtgaarden MW, Noordzij M, van Biesen W, Couchoud C, Cancarini G, Bos WJ, et al. Conservative care in Europe--nephrologists' experience with the decision not to start renal replacement therapy. Nephrol Dial Transplant. 2013;28(10):2604-12

12. Morton RL, Turner RM, Howard K, Snelling P, Webster AC. Patients who plan for conservative care rather than dialysis: a national observational study in Australia. Am J Kidney Dis. 2012;59(3):419-27.

13. Wong SP, Hebert PL, Laundry RJ, Hammond KW, Liu CF, Burrows NR, et al. Decisions about renal replacement therapy in patients with advanced kidney disease in the US Department of veterans affairs, 2000-2011. Clin J Am Soc Nephrol. 2016:11(10):1825-33.

14. Renal Physicians Association. Shared Decision-Making in the Appropriate Initiation of and Withdrawal from Dialysis (Clinical Practice Guideline). 2nd ed. Rockville; 2010

15. Parvez S, Abdel-Kader K, Pankratz VS, Song MK, Unruh M. Provider knowledge, attitudes, and practices surrounding conservative Management for Patients with advanced CKD. Clin J Am Soc Nephrol. 2016:11(5):812-20.

16. Morton RL, Tong A, Howard K, Snelling P, Webster AC. The views of patients and carers in treatment decision making for chronic kidney disease: systematic review and thematic synthesis of qualitative studies. BMJ. 2010;340:C112.

17. Evangelidis N, Tong A, Manns B, Hemmelgarn B, Wheeler DC, Tugwell P, et al. Developing a set of Core outcomes for trials in hemodialysis: an international Delphi survey. Am J Kidney Dis. 2017;70(4):464-75.

18. Urquhart-Secord R, Craig JC, Hemmelgarn B, Tam-Tham H, Manns B, Howell M, et al. Patient and caregiver priorities for outcomes in hemodialysis: an international nominal group technique study. Am J Kidney Dis. 2016:68(3):444-54.

19. Janssen IM, Gerhardus A, von Gersdorff GD, Baldamus CA, Schaller M, Barth $C$, et al. Preferences of patients undergoing hemodialysis - results from a questionnaire-based study with 4,518 patients. Patient Prefer Adherence. 2015:9:847-55.

20. Porter ME. What is value in health care? N Engl J Med. 2010;363(26):2477-81.

21. Porter ME, Larsson S, Lee TH. Standardizing patient outcomes measurement. N Engl J Med. 2016;374(6):504-6.

22. Davies SJ, Russell L, Bryan J, Phillips L, Russell Gl. Comorbidity, urea kinetics, and appetite in continuous ambulatory peritoneal dialysis patients: their interrelationship and prediction of survival. Am J Kidney Dis. 1995;26(2):353-61.

23. Levey AS, Coresh J, Greene T, Stevens LA, Zhang YL, Hendriksen S, et al. Using standardized serum creatinine values in the modification of diet in renal disease study equation for estimating glomerular filtration rate. Ann Intern Med. 2006;145(4):247-54

24. Hays RD, Kallich JD, Mapes DL, Coons SJ, Carter WB. Development of the kidney disease quality of life (KDQOL) instrument. Qual Life Res. 1994;3(5): 329-38.

25. Korevaar JC, Merkus MP, Jansen MA, Dekker FW, Boeschoten EW, Krediet RT et al. Validation of the KDQOL-SF: a dialysis-targeted health measure. Qual Life Res. 2002;11(5):437-47

26. Sedgwick P. Incidence rate ratio. BMJ. 2010;341:c4804.

27. Thompson SG, Barber JA. How should cost data in pragmatic randomised trials be analysed? BMJ. 2000;320(7243):1197-200.

28. Mihaylova B, Briggs A, O'Hagan A, Thompson SG. Review of statistical methods for analysing healthcare resources and costs. Health Econ. 2011; 20(8):897-916. 
29. Wongrakpanich S, Susantitaphong P, Isaranuwatchai S, Chenbhanich J, Eiam-Ong S, Jaber BL. Dialysis therapy and conservative Management of Advanced Chronic Kidney Disease in the elderly: a systematic review. Nephron. 2017;137(3):178-89.

30. Foote C, Kotwal S, Gallagher M, Cass A, Brown M, Jardine M. Survival outcomes of supportive care versus dialysis therapies for elderly patients with end-stage kidney disease: a systematic review and meta-analysis. Nephrology (Carlton). 2016;21(3):241-53.

31. Brown MA, Collett GK, Josland EA, Foote C, Li Q, Brennan FP. CKD in elderly patients managed without dialysis: survival, symptoms, and quality of life. Clin J Am Soc Nephrol. 2015;10(2):260-8.

32. Hussain JA, Mooney A, Russon L. Comparison of survival analysis and palliative care involvement in patients aged over 70 years choosing conservative management or renal replacement therapy in advanced chronic kidney disease. Palliat Med. 2013;27(9):829-39.

33. Murtagh FE, Marsh JE, Donohoe P, Ekbal NJ, Sheerin NS, Harris FE. Dialysis or not? A comparative survival study of patients over 75 years with chronic kidney disease stage 5. Nephrol Dial Transplant. 2007;22(7):1955-62.

34. Chandna SM, Da Silva-Gane M, Marshall C, Warwicker P, Greenwood RN Farrington K. Survival of elderly patients with stage 5 CKD: comparison of conservative management and renal replacement therapy. Nephrol Dial Transplant. 2011;26(5):1608-14.

35. Hussain JA, Flemming K, Murtagh FE, Johnson MJ. Patient and health care professional decision-making to commence and withdraw from renal dialysis: a systematic review of qualitative research. Clin J Am Soc Nephrol. 2015;10(7):1201-15.

36. Tsai HB, Chao CT, Chang RE, Hung KY, COGENT Study Group. Conservative management and health-related quality of life in end-stage renal disease: a systematic review. Clin Invest Med. 2017;40(3):E127-E34.

37. Da Silva-Gane M, Wellsted D, Greenshields H, Norton S, Chandna SM, Farrington K. Quality of life and survival in patients with advanced kidney failure managed conservatively or by dialysis. Clin J Am Soc Nephrol. 2012; 7(12):2002-9.

38. Yong DS, Kwok AO, Wong DM, Suen MH, Chen WT, Tse DM. Symptom burden and quality of life in end-stage renal disease: a study of 179 patients on dialysis and palliative care. Palliat Med. 2009:23(2):111-9.

39. De Biase V, Tobaldini O, Boaretti C, Abaterusso C, Pertica N, Loschiavo C, et al. Prolonged conservative treatment for frail elderly patients with end-stage renal disease: the Verona experience. Nephrol Dial Transplant. 2008;23(4) 1313-7

40. Seow YY, Cheung YB, Qu LM, Yee AC. Trajectory of quality of life for poor prognosis stage 5D chronic kidney disease with and without dialysis. Am J Nephrol. 2013;37(3):231-8

41. Visser A, Dijkstra GJ, Kuiper D, de Jong PE, Franssen CF, Gansevoort RT, et al. Accepting or declining dialysis: considerations taken into account by elderly patients with end-stage renal disease. J Nephrol. 2009;22(6):794-9.

42. Teo BW, Ma V, Xu H, Li J, Lee EJ. Profile of hospitalisation and death in the first year after diagnosis of end-stage renal disease in a multi-ethnic Asian population. Ann Acad Med Singap. 2010;39(2):79-87.

43. Carson RC, Juszczak M, Davenport A, Burns A. Is maximum conservative management an equivalent treatment option to dialysis for elderly patients with significant comorbid disease? Clin J Am Soc Nephrol. 2009;4(10):1611-9.

44. Shum CK, Tam KF, Chak WL, Chan TC, Mak YF, Chau KF. Outcomes in older adults with stage 5 chronic kidney disease: comparison of peritoneal dialysis and conservative management. J Gerontol A Biol Sci Med Sci. 2014;69(3):308-14.

45. Rodriguez Villarreal I, Ortega O, Hinostroza J, Cobo G, Gallar P, Mon C, et al. Geriatric assessment for therapeutic decision-making regarding renal replacement in elderly patients with advanced chronic kidney disease. Nephron Clin Pract. 2014;128(1-2):73-8.

46. Morton RL, Snelling P, Webster AC, Rose J, Masterson R, Johnson DW, et al. Factors influencing patient choice of dialysis versus conservative care to treat end-stage kidney disease. CMAJ. 2012;184(5):E277-83.

47. Lee CP, Chertow GM, Zenios SA. A simulation model to estimate the cost and effectiveness of alternative dialysis initiation strategies. Med Decis Mak. 2006;26(5):535-49.

48. Teerawattananon Y, Mugford M, Tangcharoensathien V. Economic evaluation of palliative management versus peritoneal dialysis and hemodialysis for end-stage renal disease: evidence for coverage decisions in Thailand. Value Health. 2007;10(1):61-72.
49. Morton RL, Kurella Tamura M, Coast J, Davison SN. Supportive care: economic considerations in advanced kidney disease. Clin J Am Soc Nephrol. 2016;11(10):1915-20.

50. Joly D, Anglicheau D, Alberti C, Nguyen AT, Touam M, Grunfeld JP, et al: Octogenarians reaching end-stage renal disease: cohort study of decisionmaking and clinical outcomes. J Am Soc Nephrol. 2003;14(4):1012-21.

51. Szeto CC, Kwan BC, Chow KM, Pang WF, Kwong WW, Leung CB, et al. Life expectancy of Chinese patients with chronic kidney disease without dialysis. Nephrology (Carlton). 2011;16(8):715-9.

52. Wong CF, McCarthy M, Howse ML, Williams PS. Factors affecting survival in advanced chronic kidney disease patients who choose not to receive dialysis. Ren Fail. 2007;29(6):653-9.
Ready to submit your research? Choose BMC and benefit from:

- fast, convenient online submission

- thorough peer review by experienced researchers in your field

- rapid publication on acceptance

- support for research data, including large and complex data types

- gold Open Access which fosters wider collaboration and increased citations

- maximum visibility for your research: over $100 \mathrm{M}$ website views per year

At BMC, research is always in progress.

Learn more biomedcentral.com/submissions 